УДК 349

DOI 10.18413/2712-746X-2020-45-1-141-147

\title{
О ПОНЯТИИ НАЛОГОВОГО ПРАВОНАРУШЕНИЯ
}

\section{ABOUT THE CONCEPT OF TAX LAW OFFICE}

\author{
P. 3. Юсупов \\ R. Z. Yusupov \\ Самарский национальный исследовательский университет \\ имени академика С.П. Королева, \\ Россия, 443086, г. Самара, Московское шоссе, 34 \\ Samara National Research University named after Acad. S.P. Koroleva, \\ 34 Moskovskoe highway, Samara, 443086, Russia \\ E-mail: r.yusupov@bk.ru
}

\begin{abstract}
Аннотация
Финансово-правовая наука сравнительно недавно приступила к исследованию такой категории, как «налоговое правонарушение». Вопросы наказуемости и общественной опасности как признаки налогового правонарушения не подвергались разработке и вызывают в настоящее время оживленные дискуссии. В связи с этим автор исследует формирование понятия «налоговое правонарушение», на которое особое влияние оказала юридическая практика Конституционного Суда РФ. Акцентировано внимание на наиболее спорных вопросах дефиниции налогового правонарушения, а именно на общественной опасности и наказуемости. Особое внимание уделено соотношению понятий «налоговое нарушение» и «налоговое правонарушение». Сделаны выводы о том, что на законодательном уровне необходимо разграничить налоговые правонарушения и налоговые нарушения, обособив последние не в специальной главе, а в отдельном разделе НК РФ, a также дифференцировать ответственность банковских организаций в зависимости от трех состояний: умышленной формы вины; неосторожной формы вины; отсутствия вины. При этом в общих положениях о налоговой ответственности должна быть сделана специальная оговорка о возможности их привлечения к налоговой ответственности при отсутствии вины.
\end{abstract}

\begin{abstract}
Financial and legal science has recently begun to study such a category as"tax offense". The issues of punishability and public danger as signs of a tax offense have not been developed and are currently causing lively discussions. In this regard, the author examines the formation of the concept of "tax offense", which was particularly influenced by the legal practice of the constitutional Court of the Russian Federation. The attention is focused on the most controversial issues of the definition of a tax offence, namely, the social danger and the punishability. Special attention is paid to the relationship between the concepts of "tax violation" and"tax offense". It is concluded that at the legislative level it is necessary to distinguish between tax offenses and tax violations, separating the latter not in a special Chapter, but in a separate section of the tax code of the Russian Federation, as well as to differentiate the responsibility of banking organizations depending on three States: intentional form of guilt; careless form of guilt; lack of guilt. At the same time, the General provisions on tax liability must contain a special clause about the possibility of bringing them to tax liability in the absence of guilt.
\end{abstract}

Ключевые слова: юридическая ответственность; налоговая ответственность; финансово-правовая ответственность; налоговые правонарушения; налоговая наказуемость; вина; виновность.

Key words: legal liability; tax liability; financial and legal responsibility; tax offenses; tax penalties; wine guilt. 


\section{Введение}

Финансово-правовая наука сравнительно недавно приступила к исследованию такой категории, как «налоговое правонарушение». Своеобразным толчком к этому послужил переход нашей страны к рыночной экономике и придание налогам и сборам совсем иной роли, так как без эффективной реализации функции налогообложения невозможно осуществление государством иных направлений его деятельности.

Следует отметить, что проблема понятия налоговых правонарушений ранее уже поднималась в юридических исследованиях, и по различным их аспектам защищены кандидатские [Рудовер, 2013; Тарло, 2013; Полякова, 2015] и докторские диссертации [Емельянов, 2005; Арсланбекова, 2009; Разгильдиева, 2011]. Однако в настоящей работе мы затронем вопросы, которые ранее или не подвергались разработке, или вызывают в настоящее время оживленные дискуссии. Особое внимание будет уделяться правовым позициям Конституционного Суда РФ, а также иных судов по наиболее спорным вопросам налоговых правонарушений. Особое внимание будет уделено наказуемости и общественной опасности как признакам налогового правонарушения.

\section{О законодательной дефиниции налогового правонарушения}

Принято считать, что впервые понятие налогового правонарушения было формализовано в части первой Налогового кодекса РФ (НК РФ) в 1998 году, что не совсем точно. Новейшие историко-правовые корни данного понятия находятся в Постановлении Конституционного Суда РФ от 17 декабря 1997 года № 20-П «По делу о проверке конституционности пунктов 2 и 3 части первой статьи 11 Закона Российской Федерации от 24 июня 1993 года «О федеральных органах налоговой полиции» ${ }^{1}$. Известно, что решения КС РФ занимают особое место в системе источников права, не относясь к классическим судебным прецедентам, но и не являясь нормативным правовым актом. Тем не менее они носят общеобязательный характер на всей территории Российской Федерации.

В указанном Постановлении отмечается: «Налоговые санкции носят не восстановительный, а карательный характер и являются наказанием за налоговое правонарушение, то есть за предусмотренное законом противоправное виновное деяние, совершенное умышленно либо по неосторожности». Фактически КС РФ, опираясь на положения теории государства и права, принципы юридической ответственности, а также накопленный опыт в формулировании дефиниций различных разновидностей правонарушений, сформулировал признаки налогового правонарушения. В частности, из указанного Постановления следует, что к их числу относятся противоправность, виновность, деяние, наказуемость. Одновременно высшая судебная инстанция указала и на необходимость разграничения мер налоговой ответственности от иных мер государственного принуждения, которые не носят карательного характера, а осуществляют иные функции. Ввиду вышесказанного, встречающиеся в научной и учебной литературе утверждения о том, что впервые легальное определение и признаки налогового правонарушения были сформулированы в НК РФ, не соответствуют действительности. Постановления КС РФ носят легальный и формальный характер и на территории Российской Федерации обязательны для исполнения всеми субъектами общественных отношений.

В настоящее время законодательная дефиниция налогового правонарушения закреплена в статье 106 НК РФ и, за исключением добавления в нее новых видов субъектов, не претерпела существенных изменений с момента вступления в силу. Так, «налоговым правонарушением признается виновно совершенное противоправное (в нарушение зако-

\footnotetext{
${ }^{1}$ Собрание законодательства РФ. 1997. № 1. Ст. 197.
} 
нодательства о налогах и сборах) деяние (действие или бездействие) налогоплательщика, плательщика страховых взносов, налогового агента и иных лиц, за которое настоящим Кодексом установлена ответственность». В статье 106 НК сформулирована классическая норма-дефиниция, но вызывает вопросы сфера распространения ее действия на главы и разделы НК РФ. Так, Раздел VI НК РФ носит название «Налоговые правонарушения и ответственность за их совершение». Согласно правилам толкования и юридической техники, для уяснения воли законодателя необходимо обращаться не только к содержанию текста статей, но и интерпретировать их названия, названия глав и разделов. Законодатель вполне логично сформулировал название Главы $16 \mathrm{HK}$, входящей в данный раздел, как «Виды налоговых правонарушений и ответственность за их совершение». Нормотворец дефинитивные нормы и нормы-принципы закрепил в Главе 15 НК РФ: «Общие положения об ответственности за совершение налоговых правонарушений». Однако название Главы 18 НК РФ «Виды нарушений банком обязанностей, предусмотренных законодательством о налогах и сборах, и ответственность за их совершение» вызывает недоумение. Суть в том, что как теория, так и юридическая практика исходят из того, что нарушение - это родовое понятие, а правонарушение является видовым понятием. В результате этого, юридическая практика пошла по пути привлечения банковских организаций к ответственности без вины, так как понятием «нарушение» охватываются все разновидности противоправных деяний, в том числе и объективно-противоправные. Между тем КС РФ в своих решениях, в том числе и связанных с вопросами налоговой ответственности, указывал, что ответственность без вины должна быть прямо предусмотрена в законе, то есть специально оговорена ${ }^{1}$. Налоговый кодекс РФ не содержит каких-либо исключений из общих правил и принципов юридической ответственности, как, например, Гражданский кодекс РФ.

В связи с этим можно утверждать, что законодатель нарушил правовые позиции высшей судебной инстанции. Законы диалектики гласят, что одно нарушение неизбежно порождает другое. Так, не выступая в принципе против возможности существования ответственности банков в налоговых отношениях без вины (при условии, что это должно быть специально оговорено в законе), нельзя не отметить, что нарушения банками обязанностей, предусмотренных законодательством о налогах и сборах, могут быть совершены умышленно, по неосторожности, а также без вины. Основополагающим началом юридической ответственности является ее индивидуализация. Между тем санкции в главе НК РФ о банковских нарушениях не носят дифференцированного характера и не зависят от умысла, или неосторожности, или отсутствия вины. В своих решениях КС РФ неоднократно указывал на необходимость соблюдения законодателем и правоприменителем принципов соразмерности и достаточности, а также обязательного учета всех обстоятельств совершенного правонарушения как при закреплении санкций, так и при их реализации ${ }^{2}$. К различным обстоятельствам совершенного правонарушения относится и

${ }^{1}$ Постановление Конституционного Суда РФ от 17 декабря 1996г. «По делу о проверке конституционности пунктов 2 и 3 части первой ст. 11 Закона Российской Федерации от 24 июня 1993 года «О федеральных органах налоговой полиции». Собрание законодательства РФ. 1997. № 1. Ст. 197.

2 Постановление Конституционного Суда РФ от 15 июля 1999 года № 11-П «По делу о проверке конституционности отдельных положений Закона РСФСР «О Государственной налоговой службе РСФСР и Законов Российской Федерации об основах налоговой системы в Российской Федерации и «Федеральных органах налоговой полиции». Собрание законодательства РФ. 1999. № 30. Ст. 3988. Постановление Конституционного Суда РФ от 17 января 2013 года № 1-П «По делу о проверке конституционности положения части 5 статьи 19.8 Кодекса РФ об административных правонарушениях в связи с жалобой общества с ограниченной ответственностью «Маслянский хлебоприемный пункт». Собрание законодательства РФ. 2013. № 4. Ст. 304; Постановление Конституционного Суда РФ от 27 апреля 2001 г. № 7 П «По делу о проверке конституционности ряда положений Таможенного кодекса Российской Федерации в связи с запросом Арбитражного 
вина, которой не придается какого-либо значения в НК РФ применительно к ответственности банков.

Нельзя не отметить и положительные тенденции, связанные с нормативным закреплением признаков противоправности и наказуемости налогового правонарушения. Из дефиниции налогового правонарушения следует, что противоправность понимается как «нарушение законодательства о налогах и сборах», а само понятие налогового законодательства раскрывается в ст. 1 НК РФ. При этом в П. 6 ч. 2 ст. 1 фактически закреплен принцип законности налоговой ответственности, заключающийся в ее установлении исключительно в НК РФ. В связи с этим наметилась положительная практика в решениях судов, заключающаяся в признании различных писем Минфина России ненормативными, а следовательно, не содержащими обязательных требований для субъектов налогового права ${ }^{1}$.

\section{Общественная опасность как признак налогового правонарушения}

Вполне традиционно признак общественной опасности налогового правонарушения вызывает оживленные дискуссии в юридической литературе. Здесь можно отметить две диаметрально противоположные позиции. Так, одни авторы полагают, что общественная опасность присуща налоговым правонарушениям [Хачатуров, Ягутян, 1995; Липинский, Мусаткина, 2017], а другие считают, что данный признак характерен исключительно для налоговых преступлений [Крохина, 2013; Брызгалин, 1995]. Еще одна группа ученых полагает, что налоговым правонарушениям свойственна вредоносность, а не общественная опасность [Гогин, 2011]. Ученые приводят различные доводы как обосновывающие наличие указанного признака, так и исключающие его, которые сводятся к формальной стороне вопроса. Для верного разрешения данного спора необходимо обратиться к роли и социальному предназначению функции налогообложения современного государства, а также применить историко-правовой метод исследования.

Известно, что в период существования СССР экономика носила плановый и административный характер. Значение налогов было минимизировано ввиду государственной и общественной собственности на орудия и средства производства. Уплата налогов напоминала перераспределение бюджетных средств между государственными органами, предприятиями, учреждениями и организациями. Финансовому законодательству того периода в принципе не было известно понятие «налоговое правонарушение». В УК РСФСР 1960 года содержалась только статья 82, закрепляющая ответственность за уклонение от уплаты налогов, совершенное в военное время. Административно-командная система экономики и управления была выстроена так, что уклонение от уплаты налогов исключалось. И если не принимать во внимание подоходный налог и некоторые другие виды платежей, взымаемых с граждан, то вред в случае неверной уплаты налога той или иной организацией был минимальный, так как средства по-прежнему оставались в государственной или общественной собственности.

суда города Санкт-Петербурга и Ленинградской области, жалобами открытых акционерных обществ "АвтоВАЗ" и "Комбинат Североникель", обществ с ограниченной ответственностью "Верность", "ВитаПлюс" и "Невско-Балтийская транспортная компания", товарищества с ограниченной ответственностью "Совместное российско-южноафриканское предприятие "Эконт" и гражданина А.Д. Чулкова». Собрание законодательства РФ. 2001. № 23. Ст. 2409. 31.

${ }^{1}$ Постановление Арбитражного суда Поволжского округа от 11 августа 2015 г. № ФО6 26227/2015. Интернет-версия СПС «Гарант» http://base.garant.ru/54196166/ (дата обращения 10.09.2016 г); Постановление Девятого арбитражного апелляционного суда от 22.11.2012 № 09АП-33404/2012-АК. Интернет-версия СПС «Гарант» http://base.garant.ru/54196166/ (дата обращения 10.09.2019 
Другое значение приобретает налог в условиях рыночной экономики, в которой преобладают организации с частной формой собственности, а также индивидуальные предприниматели. От полной и своевременной уплаты ими налогов зависит формирование бюджетов, а следовательно, и наличие возможности государством осуществлять присущие ему функции, реализовывать приоритетные проекты, выплачивать пенсии, обеспечивать национальную безопасность и так далее. Общеизвестно, что многие законы требуют и финансового обеспечения, но оно зависит от наполняемости бюджета страны. Не будет преувеличением утверждение о том, что функция налогообложения обеспечивает финансово эффективность реализации других функций. Если посмотреть глобально, то и реализация прав и свобод человека и гражданина зависит от наполняемости бюджета. Как известно, права и свободы человека и гражданина находятся в основе правового государства. Поэтому в широком смысле налоговые правонарушения тормозят построение правового государства и формирование гражданского общества. Примечательно, что в некоторых государствах с развитой рыночной экономикой налоговые правонарушения относят к деяниям, которые посягают на национальную безопасность. Естественно, непосредственным объектом налогового правонарушения выступают налоговые правоотношения, но они вплетены в целую систему социальных связей и объектов правовой охраны, поэтому налоговые правонарушения затрагивают различные сферы нормального функционирования государственно-организованного общества. В связи с изложенным выше полагаем, что признак общественной опасности характерен и для налоговых правонарушений.

На первый взгляд, признак наказуемости налогового правонарушения не вызывает каких-либо вопросов, так как сформулирован в дефиниции налогового правонарушения вполне ясно и недвусмысленно. Однако его практическая реализация в конкретных санкциях, предусмотренных НК РФ, не может не вызывать критики, существо которой состоит в нарушении принципов юридической ответственности. Мы вновь обращаемся к принципу индивидуализации, инструментом которого являются альтернативные и относительно определенные санкции. Между тем анализ санкций за налоговые правонарушения показывает, что подавляющее большинство из них сформулированы по типу безальтернативных и абсолютно определённых. С одной стороны, такие конструкции санкций являются ограничением для субъективизма правоприменителя и минимизируют коррупционные риски, а с другой - грубо нарушают принцип индивидуализации, так как правовых средств в виде обстоятельств, смягчающих налоговую ответственность, для этого явно недостаточно.

Рассматривая наказуемость как признак налогового правонарушения, нельзя не обратить вниманию на двойственность юридической природы пени. Так, о ней не говорится как о налоговом наказании в ст. $114 \mathrm{HK}$, а по факту в большинстве случаев осуществляется кумуляция санкции, предусмотренной конкретной нормой об уклонении от уплаты налогов и пени. Если проводить аналогию с административной ответственностью, а налоговая с ней связана глубокими генетическими корнями, то ее юридическая природа близка к дополнительному наказанию и не сводится только к компенсационному предназначению.

\section{Заключение}

Проведенное исследование развивает теории налоговой ответственности и налогового правонарушения, а в случае восприятия указанных нами предложений по совершенствованию законодательства оно может быть положено в основу ряда законопроектов, которыми должны быть внесены изменения в Налоговый кодекс РФ.

Кроме того, считаем необходимы отметить, что на законодательном уровне необходимо разграничить налоговые правонарушения и налоговые нарушения, обособив последние не в специальной главе, а в отдельном разделе, а также дифференцировать от- 
ветственность банковских организаций в зависимости от трех состояний: умышленной формы вины; неосторожной формы вины; отсутствия вины. При этом в общих положениях о налоговой ответственности должна быть сделана специальная оговорка о возможности их привлечения к налоговой ответственности при отсутствии вины. Следует провести ревизию налоговых санкций, сформулировав их по типу относительно определенных, что позволит должным образом индивидуализировать налоговую ответственность правонарушителя.

Внесение подобного рода изменений будет способствовать повышению уровня правопорядка и законности. Выявленное нами игнорирование правоприменителем требований правовых принципов и принципов юридической ответственности в настоящее время негативным образом сказывается на качестве законности и правопорядка.

\section{Список литературы}

1. Арсланбекова А.3. 2009. Финансово-правовые санкции в системе мер юридической ответственности: Автореф. дис. ... д-ра юрид. наук. Саратов, 20 с.

2. Емельянов А. С. 2005. Реализация охранительной функции финансового права: Автореф. дис. ...канд. юрид. наук. Москва, 22 с.

3. Крохина Ю. А. 2013. Финансово-правовая ответственность - необходимый атрибут правового государства. Правовое государство: теория и практика, 2: 69-72.

4. Липинский Д.А., Мусаткина А.А. 2017. К вопросу о субъективной стороне налоговых правонарушений. Налоги и налогообложение, 2: 1-20.

5. Полякова С. А. 2015. Финансово-правовая ответственность за нарушение бюджетного законодательства: Автореф. дис. .... канд. юрид. Наук, 20 с.

6. Гогин А.А. 2011. Правонарушение как конфликтное деяние. Вектор науки Тольяттинского государственного университета. Серия Юридические науки, 1: 48-53

7. Хачатуров Р.Л., Ягутян Р.Г. 1995. Юридическая ответственность. Тольятти: Академия бизнеса и банковского дела: $220 \mathrm{c.}$

8. Саттарова Н.А. 2006. Принуждение в финансовом праве. М., Юрлитинформ, 392 с.

9. Брызгалин А.В. 1995. Уклонение от уплаты налогов: правонарушение или объективное явление? Закон, 4:110-113

10. Игнатьева С. В. 2010. Налоговые правонарушения как основание для привлечения к налоговой ответственности. Вестник Академии экономической безопасности МВД России, 3: 45-48.

12. Разгильдиева М.Б. 2011. Теория финансово-правового принуждения и сферы его применения: Автореф. дис. ...д-ра юрид. наук. Саратов, 58 с.

13. Рудовер Ю.В. 2013. Финансово-правовое регулирование ответственности за нарушение законодательства о налогах и сборах: Автореф. дис. ...канд. юрид. наук. Москва, 21 с.

14. Тарло А.Е. 2013. Ответственность казны: финансово-правовые аспекты: Автореф. дис. ...канд. юрид. наук. Москва, 21 с.

\section{References}

1. Arslanbekova A.Z. 2009. Financial and legal sanctions in a portfolio of juridical responsibility measures: Doctor of Juridical Sceince thesis. Saratov, $20 \mathrm{p}$.

2. Emel'janov A.S. 2005. The realization of the security function of the financial law: Doctor of Juridical Sceince thesis. Moscow, $22 \mathrm{p}$.

3. Krokhina Ju.A. 2013. Finansovo-pravovaya otvetstvennost' - neobkhodimyi atribut pravovogo gosudarstva. [Financial and legal responsibility - a necessary attribute of a law-based State]. Pravovoe gosudarstvo: teorija i praktika. 2: 69-72.

4. Lipinskij D.A., Musatkina A.A. 2017. K voprosu o sub'ektivnoj storone nalogovyh pravonarushenij [Regarding the mental element of the tax offence] Nalogi i nalogooblozhenie. 2: pp. 120. DOI: 10.7256/2454-065X.2017.2.22116.

5. Poljakova S.A. 2015. Financial and legal responsibility for the budget legislation offence: Doctor of Juridical Sceince thesis. 20 p. 
6. Gogin. A.A. 2011. Pravonarushenie kak konfliktnoe deyanie. [Offence as a conflict act]. Vector nauki Tolyattinskogo gosudarstvennogo universiteta. Yuridicheskiye nauki, 1: 48-53.

7. Khachaturov R.L., Yagutyan R.G. 1995. Yuridicheskaya otvetstvennost'. [Legal liability.] Togliatti, Akademiia biznesa I bankovskogo dela. 220 p.

8. Sattarova N.A. 2006. Prinuzhdenie v finansovom prave. [Coercion in terms of financial law.] Moscow, Jurlitin-form. 392 p.

9. Bryzgalin A.V. 1995. Uklonenie ot uplaty nalogov: pravonarushenie ili ob"ektivnoe yavlenie? [Paying taxes evasion: an offence or an objective phenomenon?]. Zakon, 4: 110-113.

10.. Ignatieva S.V. 2010. Nalogovye pravonarusheniya kak osnovanie dlya privlecheniya $\mathrm{k}$ nalogovoi otvet-stvennosti. Tax offence as a foundation for the tax liability. Vestnik Akademii ekonomicheskoi bezopasnosti MVD Rossii. 3. 45-48

12. Razgil'dieva M.B. 2011. Theory of financial and legal enforcement and its scope of application: Doctor of Juridical Sceince thesis. Saratov, $58 \mathrm{p}$.

13. Rudover Ju.V. 2013. Financial and legal regulation of the responsibility for the tax and duties law offence: Doctor of Juridical Sceince thesis. Moscow, $21 \mathrm{p}$.

15. Tarlo A.E. 2013. [Treasury responsibility: financial and legal aspects: Doctor of Juridical Sceince thesis]. Moscow, $21 \mathrm{p}$.

\section{Ссылка для цитирования статьи For citation}

Юсупов Р.3. 2020. О понятии налогового правонарушения. NOMOTHETIKA: Философия. Социология. Право. 45 (1): 141-147. DOI 10.18413/2712-746X-2020-45-1-141-147

Yusupov R.Z. 2020. About the concept of tax law office. NOMOTHETIKA: Philosophy. Sociology. Law.45 (1): 141-147. (in Russian). DOI 10.18413/2712-746X-2020-45-1-141-147 